\title{
Entre história e historiografia: alguns apontamentos sobre a cultura política, 1820-1840
}

Between History and Historiography:

Some Observations Concerning

Political Culture, 1820-1840

\section{lara Lis Schiavinatto}

Professora no Departamento de Multimeios, Mídia e Comunicação da Universidade Estadual de Campinas

\section{Resumo}

Trata-se de assinalar um debate historiográfico sobre a presença das camadas subalternas e suas práticas políticas durante o governo da Praia e a Praieira. Enfatiza-se a noção de incompletude da Independência, a reordenação do jogo político com a emergência das instâncias do partido e da província, e as disputas políticas travadas.

\section{Abstract}

The aim of this paper is to stress a historiographical debate concerning the presence of the lower classes and its political practices during the so called Praia and Praieira government. It emphasizes the notion of incompleteness of the Brazilian Independence, the rearrangements of the political game due to the emergence of political and party power, and political quarrels as well.

\section{Palavras-chave}

modernização, representações políticas, práticas políticas, conflitos, historiografia

\section{Keywords}

modernization, political representations, political practices, conflicts, historiography 
Trata-se de uma gama de trabalhadores, homens livres pobres, escravos, libertos, de ofícios, e de diversas etnias que poderiam se congregar de maneiras distintas. Neste leque pode-se arrolar: canoeiros, alfaiates, caixeiros, carregadores e mercadores de açúcar, capatazes do porto, boceteiras, soldados, pequenos comerciantes nacionais, soldados, capineiros, pedreiros, padeiros, trabalhadores domésticos, cozinheiras, mucamas, jornaleiros, aprendizes livres e libertos. Marcus Carvalho e Marcelo Mac Cord indicam as regiões do Recife onde preponderavam uns e outros. CARVALHO, Marcus. Liberdade: rotinas e rupturas do escravismo, Recife, 1822-1850. Recife: Ed. UFPE, 1998; MAC CORD, M. O Rosário de D. Antônio. Irmandades negras, alianças e conflitos na história social do Recife 1848-1872. Recife: Fapesp/Editora Universitária UFPE, 2005

Neste sentido, as noções de "desagregação do mundo colonial" de Sérgio Buarque de Holanda e de revolução para qualificar este período da história do Brasil sinalizam para a intensificação das tensões entre modernidade e tradição. HOLANDA, Sérgio Buarque de (dir.). História Geral da Civilização Brasileira. São Paulo: Difel, 1985, tomo II, volume I.
Em texto bem escrito e articulado talvez não fique tão claro, à primeira vista, sua urdidura que vai da história à historiografia e vice-versa. 0 texto de Marcus Carvalho e Bruno Câmara entrecruza a história social do trabalho, os homens livres pobres, libertos, escravos, de várias etnias, as lideranças das camadas subalternas, os homens arregimentados em tropas em Pernambuco, com destaque para o Recife', e a Praieira. Há um esforço de sistematizar uma interpretação mais geral a respeito da Praieira através da sintese que mostra um amplo domínio das fontes, alargadas para o processo-crime, a devassa, a biografia. Estes são textos, aqui na qualidade de documentos, de forte caráter político por motivos especificos: a memória tecida e escolhida na biografia, os pertencimentos sociais e suas disputas no processo crime e mesmo a definição de crime naquela situação, afora o cotejamento com as fontes em torno dos mesmos sujeitos de proa em 1840, ampliando o recorte para o período entre 1820-30 no intuito de iluminar sua trajetória, seus compromissos políticos, suas escolhas.

É estratégico tratar da Praieira na cultura política do liberalismo constitucional da primeira metade dos oitocentos no Brasil. Acontecida em Pernambuco, ela permite retomar o tema da organização dos poderes políticos e administrativos que vão da localidade à corte, passando pela instância da província, o tema da autonomia e liberdade em situações precárias ou não. Liberdade e autonomia estavam em voga e eram almejadas por parcelas distintas das elites e das camadas subalternas por razões especificas e algumas em comum. Esta agenda política tensionou bastante as práticas paternalistas e/ou os modos de vida tradicionais ${ }^{2}$. A Praieira permite assim problematizar a cultura política da provincia, do partido, da eleição, da luta armada e da heterogeneidade social deste movimento. Ademais, possibilita a interlocução com outros movimentos sociais e políticos da primeira metade do século XIX desde a radicalidade de $1817 \mathrm{em}$ Pernambuco.

A Praieira, numa chave historiográfica, encerra o Ciclo das Insurreições Liberais do Nordeste, porém seu desfecho e repercussões reforçaram demais a sentença histórica de que a centralização do poder monárquico se deu em prol apenas das elites centralizadoras em torno de D. Pedro II sediadas na corte do Rio de Janeiro e contribuíram para a idéia de seu governo pacificado(r). A ela se ligaria a força do Partido Conservador, o sucesso da Política de Conciliação, o eixo de autoridades do Poder Moderador, da Vitaliciedade do Senado, do Conselho de Estado. 0 texto se afasta da força incontrolável da corte, da força imperiosa dos poderes centralizadores, sem esquivar-se de entender seus rebatimentos e acertos para os envolvidos neste movimento no Recife de 1848-49. Antes, pelo contrário, procura esmiuçar, no microcosmo os significados da Praieira para as camadas subalternas e como ocorreu o processo de politização destas camadas tão diversificadas social e etnicamente neste momento. Por que tanta gente, tão diversa, pegou em armas e correu riscos? Encanta, declaram os autores, a complexidade da Praieira, ao ser questão partidária que envolve ainda os conflitos políticos do interior de Pernambuco, encanta pela heterogeneidade dos sujeitos envolvidos. Ou seja, assinalam a politização das camadas subalternas na Praieira principalmente no período recortado entre 1848-49 durante a luta armada.

Neste viés, os autores dialogam com a noção de incompletude da Independência. Na Praieira se concretizaria, em tese, a agenda social e econômica aberta pela Independência que transformara a política. Haveria 
3

Este argumento apareceu em NABUCO. J. Um Estadista do Império. São Paulo/Rio de Janeiro: Cia Ed. Nacional/Civilização Brasileira, 1936. cap.3. Em QUINTAS, Amaro. O Sentido Social da Revolução Praieira. Recife: UFPe/Editora Universitária, 1977, especialmente no artigo 0 Sentido Social da Revolução Praieira. Ensaio de Interpretação. Ele assim define a Praieira: foi mais uma resultante desse estado de desequilibrio econômico-social, dessa insatisfação existente no meio da massa, do que mesmo um movimento provocado por causas meramente políticas (p.8). E ainda nesta clave explica a causa de sua derrota: 0 insucesso da revolta é uma resultante da deficiente organização revolucionária da massa. 0 potencial revolucionário do povo não foi bem aproveitado. (p.42).

4

Ver HOMEM, F. S. Torres. 0 Libelo do Povo e ROCHA, Justiniano José da. Ação, Reação, Transação: duas palavras acerca da atualidade politica do Brasil. MAGALHÃES JÚNIOR, R. (org.). Três Panfletários do segundo reinado. São Paulo: Ed. Nacional, 1956. p.45-126 e p.163218

5

Compensa observar esta cativada tradição de estadistas que escrevem, dirigem, governam no século XIX, sobretudo na monarquia e redunda em uma visão positiva do próprio Império. Esta linhagem abarca de José Bonifácio a Joaquim Nabuco, no entanto, me parece, vários estudos, entre eles os dedicados a Cipriano Barata de Marco Morel, os de Marcus de Carvalho sobre lideranças populares, o Principe Oba de Eduardo Silva e Domingos Sodré de João José Reis, delimitam e criticam esta tradição homogeneizadora e elitista dos estadistas como aqueles talhados para o exercício do governo. MOREL, Marco. Cipriano Barata na sentinela da liberdade. Salvador: Academia de Letras da Bahia/ Assembléia Legislativa do Estado da Bahia, 2001. SILVA, Eduardo. Dom Oba II d'África, o príncipe do povo: vida, tempo e pensamento de um homem de cor. São Paulo: Cia das Letras, 1997. REIS, João José. Domingos Sodré. Um sacerdote africano. Escravidão, liberdade e candomblé na Bahia do século XIX. São Paulo: Cia das Letras, 2008. CARVALHO, Marcus. Liberdade: rotinas e rupturas do escravismo, Recife, 1822-1850. Recife: Ed. UFPE, 1998 e do mesmo autor: Os nomes da Revolução: lideranças populares na Insurreição Praieira, Recife 1848-1849. Revista Brasileira de História. São Paulo, v. 23, n. 45, p.209-238, 2003; CARVALHO, Marcus. A "Revolução de Novembro", a populaça do Recife e suas lideranças em 1848. LIBBY, D. C. \& FURTADO, J. F. (orgs.). Trabalho Livre. Trabalho Escravo. Brasil e Europa, séculos XVIII e XIX. São Paulo: Annablume, 2006. um grande eixo entre as décadas de 1820 e 1840 que cumpre e amplia a cultura política do liberalismo constitucional, que vai da política para o social, daí a ênfase no caráter social da Praieira em detrimento de sua conotação política ${ }^{3}$. Estes dois argumentos se entrecruzam e reforçam uma linearidade estrita entre tais décadas e ao fim e ao cabo a Praieira se agiganta porque cumpre um programa social maior e entreaberto na Independência.

Talvez se pudesse aventar que as relações entre 1820 -40 sejam mais delicadas e nuançadas, pois a década de 1840 agencia uma memória deste passado por parte dos sujeitos sociais, traz o peso das derrotas políticas, as diversas noções de autonomia e liberdade disputadas na província e na corte em seu nome e tal procedimento empalidece certas especificidades do jogo político e social entre 1837 e 1842, quando a coalização ampla e tensa em Pernambuco aliou liberais e conservadores, e seu esgarçamento, por razões várias, acarretou na fundação do Partido da Praia.

A chave interpretativa da incompletude dissocia político e social, quando pensá-los articulados por meio dos sujeitos em jogo - em suas redes de solidariedades verticais e horizontais, de suas disputas e distinções, seus valores e estratégias -, seja mesmo parte da esfera política e de uma história social da política. Isto viabiliza matizar mais as diferenças lá postas, entre os contemporâneos e suas tradições, e as diferenças entre nossa condição contemporânea, nossa escrita da história, este tempo do passado. Neste horizonte, explicita-se também a recomposição destes passados à luz de nossa cultura política e historiográfica. Trata-se de indagar os agenciamentos entre diversas temporalidades, seus usos e significados. Logo, a incompletude da Independência pode empalidecer dinâmicas políticas e sociais e favorecer demais um único fio com fim e finalidade. Esta chave interpretativa da incompletude, em um efeito boomerangue, agencia história e política. Ela surgiu em meados do oitocentos, ao tratar das relações entre 1820 e 1840, funcionando em parte para indicar quem herdera qual quinhão da Independência ou reclamar a tarefa ainda não cumprida que assim angariava o direito ou o privilégio de orientar o presente 4 . A compreensão do passado legitimava e justificava a ação do presente. Não à toa, foi um tema caro a uma série de autores - vetorizados por uma dada noção de estadista ${ }^{5}$ - que reverberaram na historiografia.

Também a noção de incompletude remete a uma idéia de déficit e de carência que tendem a se eternizar, porque não se resolve ou é superado, não consegue ser posto definitivamente no passado, encerrado. Isto no limite pode parecer que sempre estamos inseridos no mesmo, nas mesmas malhas de poder, no mesmo paternalismo de lá e cá, sem esmiuçar as reinvenções destas práticas, suas repetições de onde emergem os processos de diferenciação, suas miudezas e distinções que não configuram o mesmo sempre. Por outro lado, esta incompletude refreia o basculamento social e político que o processo de autonomização do Brasil, como corpo político autônomo, enredou e os esforços das elites de maneiras várias para deter, recompensar, negociar a presenças, os interesses, as autonomias das camadas subalternas. Estas estratégias foram da violência aberta aos soldos, do trabalho compulsório aos dispositivos constitucionais, principalmente acerca da representação e da criminalização de práticas e posses destas camadas subalternas. Grosso modo, este noção de incompletude acabou colaborando para engendramento da indagação quanto à presença e inserção das camadas populares em meio a estas tensões políticas. 
GOUVÊA, Maria. de Fátima S. Política provincial na formação da monarquia constitucional brasileira. Almanack braziliense, n.7, maio 2008.

7

Maria do Socorro Ferraz apresenta esta diversidade de liberais em Pernambuco especialmente em Liberais \& Liberais. Guerras Civis em Pernambuco no Século XIX. Recife: Ed. Universitária da UFPE, 1996.

8

Repare-se que a localidade, neste momento, é uma identidade plástica e alterável conforme seu redesenho e continua (re)territorialização a fim de atender às conjunturas de mando local e sua devida expressão no sistema eleitoral, conforme indicado por Marcus Carvalho e Bruno Câmara no texto.
A experiência da Praieira, no artigo, faz aparecer a tensão cotidiana e a disputa acirrada entre a localidade, a centralidade do Recife sob o novo regime de modernização implementado pelo barão de Boa Vista, as áreas de fazenda e açúcar, engenhos e bangüês, do interior, a província e o poder central da monarquia, em meio as disputas politicas e partidárias. As configurações identitárias "província" e "partido" eram recentes na cultura política da época e no maquinário monárquico liberal, constitucional, administrativo, montado a partir da Independência e da experiência política da década de 1830.

Entre 1808-21, segundo Fátima Gouvêa ${ }^{6}$, os termos província e capitania se intercalavam com ambivalência. A partir de 1821 através das medidas das Cortes Vintistas, com a criação do Conselho de ProcuradoresGerais das Provincias do Brasil e com a Carta Constitucional de 1824, que instituiu os eleitores de província no novo sistema de governo constitucional, a província ganhou uma realidade política-administrativa própria, adensada, desde aí pela representação e pelo sistema eleitoral. Ela tornouse uma instância de poder regional que mediava, funcionava como canal, esfera de decisão, espaço de representação da província no império e na corte, e também se aparatou até a década de 1830. Sua criação mostra um interesse de um governo direto do governo central que precisa de mediadores em toda parte da mesma forma, mediadores na negociação e implantação de ações políticas, para ampliação de alianças, eleitorais muitas vezes, e controle das redes comerciais, dos poderes locais e suas elites. 0 Ato Adicional de 1834 deteve-se nela ao transformar os Conselhos Gerais em Assembléias Provinciais Legislativas, ampliou sua importância na medida em que permitia a nomeação de oficiais de fazenda e da justiça pelas autoridades provinciais, e tornava o orçamento provincial responsabilidade exclusiva da Assembléia, sem desfazer-se da localidade ou da prerrogativa centralizadora da nomeação do presidente da Província. 0 alcance e a natureza de sua autonomia foram diminuidos com a Lei Complementar de 1837, ao retirar a sua capacidade de nomear os oficiais de justiça e fazenda. A assembléia provincial, contudo, continuou sendo um espaço de participação e exercício da cidadania e representação políticas a qual o sistema eleitoral era intrínseco e este era um mecanismo de inserção de grupos sociais e políticos heterogêneos ao projeto da monarquia constitucional, que então lutava duramente para se instituir como a centralização política, sem a fragmentação do império do Brasil ou comprometimento da escravidão. A novidade da província de 1820-22 com o exercício efetivo de autonomia em Pernambuco era um legado político vivo para muitos desta elite agrária e mercantil. Sem nenhuma inocência, pois sabiam e vários conheciam na pele o custo alto - com a licença devida à custa ainda de sangue, fazendas e vidas - de bater-se pela autonomia. E não havia nisto necessariamente uma continuidade do mesmo, do desde sempre, das estruturas de poder7. Agora, pode-se perguntar em que variava estar sob a condição partidária? Tratase, pois, de uma identidade política mais estável que visava ser legítima, programática, permanente pública e objetiva a assembléia, os postos nas instâncias políticas e administrativas, filha do liberalismo constitucional e da representação - prerrogativas, naquela altura, sem as quais não aconteceria. Neste sentido, a Praieira significou uma disputa acirrada entre as elites em Pernambuco pelo governo da província que abarcava o processo de modernização de Pernambuco, as instâncias de governo e a representação da localidade 8 à corte. 
9

CARVALHO, Marcus. A "Revolução de Novembro", a populaça do Recife e suas lideranças em 1848. LIBBY, D. C. \& FURTADO, J. F. (orgs.). Trabalho Livre. Trabalho Escravo. Brasil e Europa, séculos XVIII e XIX. São Paulo: Annablume, 2006. p.453.

10

Izabel Marson adverte que existia um projeto de rebelião moldado na delegacia de polícia, havendo uma superdimensionamento das ações das camadas subalternas entre fins de $1848 \mathrm{e}$ inicio de 1849. Contudo, não nega a presença, a força, e os interesses destas camadas subalternas na década de 1840 . MARSON, Isabel. 0 Império do Progresso. A Revolução Praieira em Pernambuco (1842-1855). São Paulo: Brasiliense, 1987. p.142.

11

Para este debate ver CARVALHO, Marcus. A

"Revolução de Novembro", a populaça do Recife e suas lideranças em 1848. In LIBBY, D. C. \& FURTADO, J. F. (orgs.). Trabalho Livre. Trabalho Escravo. Brasil e Europa, séculos XVIII e XIX. São Paulo: Annablume, 2006. Também deste autor Os nomes da Revolução: lideranças populares na Insurreição Praieira, Recife 18481849. Revista Brasileira de História. São Paulo, v.23, n.45, p.209-238, 2003 e MARSON, Isabel. Politica e Memória: a Revolução Praieira e suas fontes. Idéias. Campinas 5 (1), p.75-129, janjun., 1998. Este vocabulário político explicita a premeditação, o calculo, o projeto, a espontaneidade, as intenções dos envolvidos na ação política, logo a escolha do termo define muitas vezes o encaminhamento da explicação. Hannah Arendt já apontou justamente a natureza multifacetada da noção de revolução e seus desdobramentos para analise. Da Revolução. São Paulo: Ática, 1988.
Neste contexto, o processo eleitoral, o ato de votar, o calendário eleitoral, as formas de coerção e adesão entre leitores, votantes, eleitos, entremeados aos debates na câmara e na imprensa, ganharam uma importância que vale ponderar. Porque era uma esfera privilegiada da politização destas camadas subalternas, na qual se fizeram presentes e foram disputados por parte dos partidos da Praia e Conservador. Entre 1844-47, a Praia se comprometeu com bandeiras das camadas populares nucleadas pelas condições do mundo do trabalho. Entre 1846-48, os dois partidos debateram o desemprego crescente em Pernambuco no intuito de conquistar o votante primário, em geral, homens de oficio, rendeiros, pequenos proprietários. 0 próprio Marcus Carvalho afirmou: A chave para se entender a ação da população engajada na revolta está na radicalização das disputas eleitorais na provincia ${ }^{9}$.

Simultaneamente, estabeleceu-se uma compreensão comum entre liberais e conservadores a respeito o recurso de pegar em armas - implicando a "populaça", inevitavelmente - era sinônimo da desrazão, do desgoverno, do último expediente em nome do direito natural, no caso a propriedade. Pegar em armas com o povo vinha carregado de um teor negativo, entretanto era difícil abrir mão desta gente na eleição e depois na ação armada. Logo, quando os praieiros se identificaram com este povo propiciaram que a polícia e as autoridades encontrassem aí elementos suficientes ${ }^{10}$, embora não unânimes na historiografia, para caracterizar um crime perpetrado contra a ordem da monarquia constitucional. Tal recurso entre a violência e a política conforme o relato do sujeito aí implicado estabeleceu um vocabulário político sobre a Praieira (movimento, sedição, insurreição, rebelião, revolta, revolução ${ }^{11}$ ) capaz de permear o testemunho, a documentação oficial, os anais, a cronologia, a imprensa, os estudos históricos; e este vocabulário reativado em uma espécie de torvelinho reatualiza este problema historiográfico e sua memória, erigindo-a em um lugar de memória da cultura política.

Neste ponto, atento para dois gêneros de acontecimentos históricos capitais no texto. Trata-se de um tipo de acontecimento político, um modo de acontecer com uma performance especifica e significativa. Para não me estender na explicação mais conceitual, sugiro o seguinte: se a greve pode ser tomada como modo de acontecer com transcorrer e ordenação próprios (re)conhecidos pelos sujeitos implicados, pode-se, por decorrência e associação, indicar, no texto comentado, dois gêneros de acontecimento cruciais para a Praieira, principalmente nas articulações e nas mediações entre as elites e as camadas subalternas, donde despontam muitas vezes as lideranças populares. E os dois se relacionam: o pegar em armas e a eleição. Pegar em armas, a luta armada, a disputa, a derrota e a vitória através das armas formavam uma variável importante e cruenta na cultura política do liberalismo constitucional e foi decisiva na Praieira. Este acontecimento presume desde a presença das tropas até o campo de batalha como se vê no início do texto, quando os praieiros são derrotados no Recife, embora crédulos de sua estratégia militar. Este acontecimento de cunho militar presume também certo basculamento da ordem e da hierarquia social que varia conforme a dramaticidade e a periculosidade da luta e do adversário. Se a tropa, o regimento militar, os homens em armas aludem à organização mais férrea, dura, autoritária, de castigos, execução sumária, ela também adensa vínculos paternalistas e códigos de confiança, de fidelidade, de agregação e ainda muita discordância e deserção. Bem como, propicia o 
12

Izabel Marson e Marcelo Mac Cord enfatizam bastante este aspecto e seu alto custo para o Partido da Praia, pois afasta e interpõe adversidades entre os praieiros e as camadas subalternas. Mac Cord assinala tais fraturas nas relações cotidianas e extra-partidárias entre homens da Praia e homens de oficio a partir do estudo das relações de solidariedade verticais e horizontais dentro da Irmandade de Nossa Senhora do rosário dos Homens Pretos da freguesia de Santo Antonio do Recife e outras irmandades de pretos e de homens de ofícios na cidade bem como suas rivalidades e distensões. Desta maneira, flagra distinções no interior destas camadas subalternas e nos seus tratos com certos praieiros de proa. MAC CORD, M. O Rosário de D. Antônio. Irmandades negras, alianças e conflitos na história social do recife 1848-1872. Recife: Fapesp/Editora Universitária UFPE, 2005 especialmente a parte 0 mundo do trabalho e o Cap. 3. MARSON, I. O Império do Progresso. A Revolução Praieira em Pernambuco (1842-1855). São Paulo: Brasiliense, 1987.

13

EISEMBERG, Peter. Modernização sem Mudança: a Indústria Açucareira em Pernambuco, 18401901. Rio de Janeiro/Campinas: Paz e Terra/ UNICAMP, 1977. aparecimento de uma liderança própria que pode ir da tribuna à farda ou não. Além disso, nesta ordem de acontecimentos, gente do povo de outras insurreições pode vir a atuar, perfilar-se.

Em outra direção, o texto sublinha o valor da eleição, como uma prática significativa e gêmea da representação e exercício da cidadania e aí realça a novidade e a importância dos meetings como evento político ordenado pelos partidos. Esta ação militar e a eleição, a representação, se entrecruzavam na Praieira enquanto maneiras da reivindicação política destas camadas subalternas e estavam em contigüidade com esta esfera pública e política institucionalizada. Percebe-se que o governo da Praia antes de 1848 não cumpriu a agenda política e social propagada às camadas subalternas no processo eleitoral12, o que acabou comprometendo a ampla e maciça adesão destas camadas no momento da guerra civil. Aqui, se posso fazer uma sugestão, talvez fosse bom voltar ao estudo da retórica política deste período em Pernambuco. Não para cair na armadilha do passado quanto à força libertária que tinha ou para ficar embasbacado em sua eloqüência, mas para entender o agenciamento entre ideário político, ação militar, jogo eleitoral, que definiram os termos desta agenda e vocabulário políticos e seus significados para os sujeitos específicos aí envolvidos.

Estes acontecimentos por si só, em seus protocolos constitutivos, abriam para uma gente que, em geral e por mediações, na década de 1840 alcançava a Assembléia na condição de votantes primários e até eleitores. Logo, o cotidiano permite flagrar a dimensão política destes acontecimentos que só se efetivam com tais camadas subalternas. Não se pode aquilatar as experiências destas camadas sob a matriz do liberalismo constitucional que, em geral, as acusa pela falta de projeto, de cálculo de longo alcance no tempo e no espaço territorial e político-administrativo, ou seja, se prenderiam a uma ação mais imediata porque procuram preservar práticas que asseguravam trabalhos, protegiam certos trabalhos e as associações entre trabalhadores e de certos ofícios como os carregadores de açúcar, os capatazes do porto, os canoeiros, os caixeiros, além de combater o desemprego para os brasileiros e, ai, buscavam alijar os portugueses do processo eleitoral e do mercado de trabalho.

Na cultura política destas camadas subalternas parte do ganho se expressa no cotidiano imediato e isto não corresponde à falta de visada política. Pelo contrário, também se valeram da representação e do jogo eleitoral e partidário para assegurar algumas condições de vida, emparedadas entre a escravidão, o recrutamento e a sobrevivência. Na falta de recursos materiais, financeiros, e devido às restrições constitucionais para adentrar o jogo da representação e do sistema eleitoral, parte dos caixeiros, soldados, pequenos negociantes nacionais, homens de oficio se viram na contingência de negociar suas reivindicações e estas apareciam em periódicos como 0 Nazareno, O Tribuno, O Regenerador do Brasil, A Voz do Brasil. Tais práticas, contudo, não impediram que as elites e os partidos modernizassem a produção e as relações de trabalho da atividade açucareira, como mostrou Peter Eisenberg ${ }^{13}$, e isto também se passava no mundo urbano. A instrumentalização da política pelo viés da modernização e do projeto da revista 0 Progresso estudado por Izabel Marson não nega ou neutraliza tais formas de viver e lutas das camadas subalternas, antes matizam estas tensões e as argúcias para se engendrar a autoridade pública de uns e outros.

Por outro lado, o artigo trata de insurreição. Privilegia também uma espécie de história de motins e gente amotinada contra a opressão exaus- 
14

CÂMARA, Bruno Augusto Dornelas. Vassoura, balcão, escritório e rua. Almanack Braziliense, n.6, novembro de 2007.

15

Sobre este tema ver: BERNARDES. Dênis A. Mendonça. O Patriotismo Constitucional: Pernambuco, 1820-1822. São Paulo/Recife: Hucitec/Fapesp/ Ed. UFPE, 2006.

Recebido para publicação em setembro de 2008 Aprovado em outubro de 2008 tiva, porque o pegar em armas escorrega mais de uma vez para modos amotinados de agir que redimensionam a noção de autonomia e que não dispensa o nexo no qual se dava uma certa coalizão. Se há um nexo forte na nacionalização do comércio a retalho é porque agregava o mais da gente: dos senhores à "raia miúda", aos homens livres pobres com e sem oficio, de várias etnias, diante do desemprego que crescia e da reordenação de certos trabalhos como viviam os mercadores e carregadores de açúcar e os capatazes do porto. 0 comércio a retalho, assim abordado, alude a uma economia moral das camadas populares, dos escravos inclusive, no cotidiano, na manutenção e acesso dos gêneros de primeira necessidade, na salvaguardar da fome, na garantia do sustento continuado, e este economia moral não emerge apenas na insurreição, mas ainda na busca por algumas regras, tal qual a expulsão de caixeiros portugueses, coisa não necessariamente desejada pelos senhores que contariam com mais mão-de-obra e seu barateamento.

Esta espécie de bandeira comum moldada no comércio a retalho relaciona armas, trabalho, eleição, reivindicação política. Bruno Câmara ${ }^{14}$ já mostrou a presença de negros, escravos, entre caixeirada do Recife, sua formação profissional prolongada e relembra a forte vinculação entre 0 senhor, o dono da bodega, do armazém de esquina, da casa comercial e os tipos de caixeiro que até pode se tornar parte da família, era um modo de solucionar inclusive a vida de uma filha. Aí, assinalou a presença e o funcionamento do nativismo ao estabelecer no "português" uma alteridade que atrapalharia o acesso a este posto. Esta foi uma bandeira forte e comum entre 1848-49, como bem mostra o artigo aqui comentado. Todavia houve um diferencial denotado pela pesquisa histórica, entre 1844-48, para estes homens das camadas subalternas, inclusive no que tange ao tema do comércio a retalho: o valer-se de uma instância entrecruzada, que se ocupada, trata publicamente e politicamente das suas reivindicações e condições no mundo do trabalho: o governo-o partido-a assembléia.

A categoria representação fora explicada em toda sorte de texto didático político, de alta retórica, em catecismos, panfletos, periódicos, desde 1820 em Pernambuco, e a noção de patriotismo constitucional15 teve aí uma ampla e variada apropriação e circulação, e agora se tornara o espaço querido, onde o que se entendia por direito, reivindicação, ganho social e político também poderiam ser encaminhados e até solucionados em certa medida através desta prática política. Estas camadas subalternas vislumbraram no âmbito da representação via sistema eleitoral uma maneira de ordenar e facilitar seu cotidiano de trabalho e seu sustento, tecendo inclusive outras redes de aproximação, solidariedade, cobranças com praieiros e conservadores, entre as irmandades como mostrou Mac Cord. Na medida em que os praieiros e os conservadores, cada uma seu turno e da sua forma, não cumpriram as promessas eleitorais, ficaram também entregues à própria sorte e às suas forças mais próximas e imediatas na guerra civil. E talvez aí o tema do comércio a retalho fosse a bandeira capaz de galvanizar o maior número de gentes e seus interesses específicos, mas também abafasse ou preterisse outras maneiras de intervir na ordenação do mundo do trabalho e, no limite, acarretou na dissociação entre votantes, eleitores e eleitos. De tantas questões entreabertas, fica mais uma a latejar: quais os aprendizados das camadas subalternas com a experiência do governo da Praia e da Praieira? 